This is an Accepted Manuscript of an article published by Taylor and Francis in Disability and Society on $30 / 11 / 17$. It is available online here:

http://www.tandfonline.com/doi/full/10.1080/09687599.2017.1401527

To cite: Williams V, Tarleton B, Heslop P, et al. Understanding disabling barriers: a fruitful partnership between Disability Studies and social practices? Disability \& Society.

\title{
https://doi.org/10.1080/09687599.2017.1401527
}

\section{Understanding Disabling Barriers:A Fruitful Partnership between Disability Studies and Social Practices?}

\section{Abstract}

Disabled people are regularly denied their human rights, since policies and laws are hard to translate literally into practice. This article aims to make connections between social practice theories and Disability Studies, in order to understand the problems faced by disabled people, using different methods to look in detail at how practices are shaped and how disabled people get excluded. Disabled people are active agents in making change, both informally on an everyday basis and through formal actions. Thus we also suggest that the insights of disabled people could bring a fresh perspective to social practice theories, by troubling the taken-for-granted in our everyday lives.

\section{Background}

The UK is a signatory of the 2007 United Nations Convention on the Rights of Persons with Disabilities (UNCRPD) and as such has instituted national legal frameworks to promote and enforce equality. The 2010 Equality Act, which incorporates the Public Sector Equality Duty, offers a legal framework to recognise and tackle discrimination across a range of protected groups, including those who are disabled. Such instruments are important tools for establishing precedents through case law, and also for alerting policy makers to the potential for legal scrutiny of their actions. For instance, during 2016 the UN Committee on the Rights of Persons with Disabilities (UN 2016, 20-21) ruled that the UK approach to austerity unfairly discriminated against disabled people.

However, there is a constant stream of evidence that human rights statements do not always translate into improved lives for disabled people. Redley et al. (2012) question the practices which enable men and women with intellectual disabilities to realise their right to vote under Article 29 of the UNCRPD, while Harwood (2016) highlights the disproportionate difficulties faced by disabled workers to enforce their employment rights. Meanwhile, Abbott (2013) considers the area of sexual 
rights for disabled people, and concludes that human rights statements can seem 'rather technical... [and] lofty and removed from everyday life' (p. 1080).

Ironically, these violations and difficulties can also apply to disabled people who are involved in monitoring and reporting on Human Rights. Bott (2016) in a series of events to monitor the UNCRPD has shared that:

'Many disabled people have been unable to attend our events because personal support is no longer available and they are virtually confined to their own homes. For those who have been able to come it feels like going back in a time warp with all the old issues, which really should have been sorted by now, being discussed - poor access to public transport because even when there are accessible places no one is enforcing them, limited access to buildings including new builds, having to share space with cars, being shut out of health screening programmes or made to feel it is your own fault because you have an impairment, big increases in compulsory treatment orders, being unable to secure a job' (Bott 2016)

Further, these barriers are not just about physical access. Very relevantly for this paper, Riddell and Watson (2011) maintain that: 'Traditional conceptualisations of equality have tended to emphasise the economic and cultural domains, but it is evident that the affective and representational are also of great importance (p. 197). When a person is made to feel as if their impairment is their own fault, as in the quotation above, that can be part of the way disability is represented, and may influence feelings and attitudes towards disabled people, as well as disabled people's own self concept (Thomas, 1999).

This paper aims to identify and understand the ways in which disabled people become excluded or disadvantaged, often by the very services which are meant to support them. It is rooted in research being carried out in partnership with [Name of partner organisation] by [Author et al.] in a large UK based project referred to as [title of project] and explores some new avenues for disabled people themselves to understand and challenge the barriers they face in the UK in the $21^{\text {st }}$ century. We are interested in disabling practices, over a wide spectrum of life domains, and we aim to explore some very different ways of conceptualising the problems faced by disabled people, via empirical research in health care, personal support services, everyday life, parenting support and in higher education. All the work we are doing is centred on disabled people's own voices, insights and actions, and much of it challenges conventional power structures that ordinarily silence the voices of disabled people.

What are social practice theories? 
In this paper, we will explore how we can apply social practice approaches to the gap which we see between equality laws and people's everyday lives. The word 'practice' is often associated with invocations to professional staff to 'do better', but social practice theories (Reckwitz 2002; Shove, Pantzar et al. 2012) are far wider and more fundamental than that. A social practice is simply something that human beings do in their lives; gardening, going out for a meal, travelling by bus and even health screening - all of these are social practices. 'Going to a consultation event' in Bott's example above can be seen as a bundle of interconnected social practices, involving care provision, public transport, health care and employment - all of which intersect in complex ways (Hui, 2017).

Theories simply help us understand how these things get done, in all their variability across different social actors and contexts. Social practice theorists take an interest in systems of social action rather than psychology or behaviour, that is, 'the structures and mechanisms that are often overlooked' (Bourdieu 1998, 3). Further, they are interested in how things get done, and how these 'doings' form patterns which are recognisable, structured and ordered (Schatzki, 2001). To be clear, this structure and ordering is not something which is imposed by policy. Practice theorists are interested in how social action itself becomes ordered via unconscious and invisible rules or patterns. To that extent, a social practice is an abstraction, but one which enables us to unravel some exclusionary barriers, and thus in some senses take forward the social model of disability (see Oliver, 2013).

Working with disabled people and their organisations who are partners in our project, this paper aims to set out a way of developing social practice theory (Schatzki, 2001; Reckwitz, 2002; Shove, Pantzar and Watson, 2012) within Disability Studies. We also consider how these ideas about social practice evolve in a field that specifically deals with inclusion/exclusion and inequalities, when so far social practice theory has been applied more to other fields, such as sustainability. Our aim is therefore twofold, both to explore what social practice theory can offer disability studies, but also what the application to disability issues might be able to offer practice theory.

\section{How social practices can cause problems for disabled people}

When considering how abusive and neglectful services can arise, policy makers often resort to explanations which invoke the prevailing 'culture'. An example is the annual report for 2013/14 by the English Care Quality Commission (CQC 2014) which attributes multiple layers of problems in health and social care to issues with 'culture', including the 'prevailing culture of paternalism [in health services]' (10). A separate example is mentioned in relation to a care home for people with dementia, where residents were left in bed until midday, there was a constant smell of urine, and a 'blasé attitude towards allegations of abuse'. The report, as so many of its kind, refers to the culture as a root cause of the problem: 
'The local council told CQC that they felt there was a poor culture among staff at the home that they couldn't pin down' (CQC 2014, 32).

The terminology of 'culture' is slippery, overused and intangible, as argued by Alvesson (2013, p. 34), and has been used both with reference to role structure (Handy, 1993) and the unconscious underlying assumptions which can shape organisational practices (Holmes, 2006). In our research, we are especially interested in the ways in which personal-professional relationships are shaped and 'naturalised' by the material arrangements within practices (Author 1 2017). In some respects this follows in the tradition of Lipsky's (1980) influential research, which revealed how frontline practitioners routinely re-shape the 'rules' of policy by interpreting them and enacting them in practice.

Although Alvesson (2013) claims that the study of culture is epistemologically distinct from the study of social structure (p. 4), we argue that theories of social practice such as Reckwitz, (2002: 250) and Shove, Pantzar and Watson (2012) can help us to unravel disabling or exclusionary ways of doing things; while practice theorists do not use the word 'culture', nevertheless as Schatzki (2001) argues, practices bind together social groups, such as the groups of nurses in a care home: "Being one of us ... can be [re]defined as participating in our practices" (p. 116). For that reason, in order to argue for social change, we need to both analyse and to disrupt the taken-for-granted order of routine social practices (Giddens, 1988: 279). We need not only an accumulation of evidence, but also some understanding of the mechanisms that prevent positive changes from happening or which support the status quo (Bhaskar et al. 2006).

Thus although we start with commonly heard invocations of 'the culture' of the workplace, our analysis does not stop at that. We are interested in applying the full range of social practice insights to those phenomena, and connecting those with ideas in Disability Studies about social exclusions and barriers. In that endeavour we draw on Disability Studies theories relating to social barriers (Oliver, 1990; Thomas, 2004) mindful of the many debates about the place of the body within disability theory (Crow, 1996; Thomas, 1999) and the complex experience of impairment as well as disabling barriers. Theories about the interconnection between impairment effects and societal contexts (Shakespeare, 2006) are very relevant to social practice theories, for instance GarlandThomson's $(2011,594)$ discussions of the 'misfit' between a disabled person and the social world. If disabled people are disadvantaged by the way things are organised in society, rather than by individual malpractice, then we need a holistic account of social practices which includes the lived experience of the person, in addition to an analysis of the elements from which social practice is organised. 
We turn next to an overview of the origins and developments of social practice theories, situating ourselves within those debates, in order to explore what might be useful for Disability Studies. We then move on to illustrate how social practice theory can be usefully applied in empirical research with disabled people, and we draw on our own data to provide brief examples of the problems faced by disabled people, how we can question and critique the ways in which social practices are shaped, and how that type of analysis can promote changes. We conclude with a discussion of some future directions.

\section{Some concerns of social practice theories}

Social science, including that relating to disability, has traditionally taken as its unit of analysis categories of human beings (for example, disabled women, people who are homeless, children with a particular characteristic) and evidence of their lives or the issues they face is understood by reference to the characteristic by which they were identified. Housley and James-Smith $(2015,153)$ point out that this categorical approach to human beings may simply reiterate and reproduce the key concerns which prompted the study. For example, a study in criminology, as Liebling (2001) shows, might group together those who are detained in prison, that being the key defining feature of interest to the researcher. This categorical approach is challenged in Disability Studies by those who consider intersectionality a key issue; a disabled woman living in poverty, who is from a minority cultural group, could experience multiple disadvantage (Moodley and Graham 2015). However, even the intersectionality stance still keeps the researcher's gaze firmly on group characteristics, albeit in a more complex and shifting fashion. The turn towards practice simply represents a different, distinct unit of analysis. Instead of conceiving of societies as amalgams of different types of people, the social practice theorist is interested in societies 'as intersections of multiple sets of recurring practices' (Schatzki 1996, 4). For instance, social practices identified and investigated in the current research [Name of project] include going into a hospital, or giving and receiving parenting support.

Each time we do things, our actions can be understood within wider patterns or shapes of activity, which develop distinctly in different societies (Shove, Pantzar and Watson, 2012). As these authors suggest, each enactment of a practice draws on an accumulation of shared knowledge, meanings and technology. The term 'social practice' is an abstraction, which refers not to just one instance or action, but to the interconnected collection of doings (Author 4 et al., 2017). A social practice can be thought of as a pattern, essentially an abstract shape which helps us to describe and understand what we do in routine ways in everyday life (Schatzki, 2001; 2017). 
An example which jumps forward to our data might be useful here: consider the practice of two people getting a lift home from a dementia activity group. In one part of our project, we have been filming the interactions that occur with people with dementia, and thanks to these two people with dementia and their volunteer driver, we were able to set up a small camera in their vehicle for one journey. How can we think about that journey as a social practice? First, we need the technology of driving, and a vehicle that is in good order. There also had to be a driver who has a driving licence, and maybe also the social, community oriented value of giving each other lifts, as well as an organising body who help facilitate and arrange volunteer drivers. This could all be situated within the wider practice of driving, or 'getting a lift', although that has particular significance for people with a dementia diagnosis, who will generally have lost their driving licence. Each time something is done it could and does add to the many different variations on doing that particular thing (Hui, 2017), and in our data we see how the lift-giving is interlaced with conversation about the day, in locating house keys, and in reminiscing. Some of this might support the independence and autonomy of the disabled passengers, but it can easily shift to positioning them as incompetent or inadequate. As Bourdieu (1998) puts it, 'the deepest logic of the social world can be grasped only if one plunges into the particularity of an empirical reality, historically located and dated (Bourdieu $1998,2)$.

Why would this be an interesting or fruitful way of looking at the concerns of disabled people? As Giddens (1988) pointed out, mundane doings can both shape and be shaped by an often unarticulated, wider set of meanings in which human beings live:

The techniques, strategies, and modes of behaviour followed by actors in circumstances of copresence, even in the most seemingly trivial aspects of their day-to-day life, are fundamental to the continuity of institutions across time and space. (275)

As disabled people continue to argue, it is the everyday structures of action around them in their lives which 'disable' or enable them, starting from the complexities of communication and interaction (Robillard, 1999; Watson, 2003) to the wider policies of community engagement and volunteering which prompt the lift-giving in the example above.

Theorists who have argued for the centrality of social practices are interested in the way in which our understandings, meaning making and our assumptions are made visible in what we do (Schatzki $1996,12)$. This approach can allow us to look more widely at societal structures, via the ways in which groups of people share ways of doing things and share their understandings about the world. 
Thus a practice approach describes 'the shared theories, ideas, beliefs or abstractly specified rules or norms that allegedly 'govern' [...] behavior' (Barnes, B. 2001, 25). Further, social practices go beyond individual action, into the realm of the social. Focusing on social practices as a unit of analysis can thus allow us to move well beyond the 'micro' gaze on one action, and can be the basis of an analysis of a community, a social group, or a religion; even widely important features of society such as power, coercion or domination can be seen as 'features of.... phenomena instituted and instantiated in practices' (Schatzki 2001, 15).

\section{Interconnections between social practices and actors}

Disability scholars are not the only ones to take an interest in how practice theory could explain and shift practices. Practice Theory approaches have been developed to understand problems faced in society today, such as sustainable practices in the light of climate change (Shove, 2010; 2014) and public health issues such as smoking (Author 4 et al., 2016). Shove et al. suggest that social practices can be thought of as being composed of three 'elements': 1) competences (skills and embodied knowledge); 2) materials or technical resources (the actual objects and things we use); 3) meanings (which are socially produced and mediated through practices) (Shove et al. 2012). Elements can shift and change over time, changing the way the actual practice is constituted. Shove et al. (2012) use the example of the social practice of driving, and demonstrate neatly how it has developed over the course of the Twentieth Century, partly as a result of changing technology, which brings in its wake the new cultural value associated with being a car owner or driver, and the development of different employment practices and social encounters.

Shove's three different types of elements (competences, materials and meanings) are produced and mediated through practices, and each social practice can thus be unpicked, in order to appreciate how it is made up. However, a single practice is not performed in isolation. Social practices intersect in complex ways with other practices, (Author 4 et al., 2017), blocking or confusing our attempts to change or make progress. The more carefully an analyst looks at actions, even in the most straightforward of practices, the more complex and entangled connections between practices are revealed. In that vein, Author 4 et al. (2017) show how material objects, time scales and professional policies all matter when considering how various hospital practices such as mealtimes and ward rounds hang together. We would contend that this interconnection between practices is 
absolutely key to understanding how things get 'stuck' and how disabling practices are perpetuated for instance in personal support and care services, in universities or in health care.

What about the people who perform the practice? Here there is a strong link with the concerns of Disability Studies. If the practice itself is the core unit of analysis, it follows that there is less emphasis in social practice theories on the social actor, which is maybe problematic for Disability Studies. According to practice theory, it is the practice itself which 'recruits' the 'practitioners' or the people who perform it (Shove et al., 2012), and it follows therefore that some groups of people (e.g. those who are disabled) may be routinely excluded from certain practices such as particular sports (Shove and Pantzar, 2007). This point chimes very strongly with our own interests in disabling practices, since we are finding (with Garland-Thomson, 2011) that some ways of doing things are exclusionary; disabled people are either disadvantaged, left out or made to feel that they are the 'problem', when trying to use public transport as seen in our first example, or as we shall see below, when obtaining materials, resources or adaptations in universities. In other words, 'recruitment' of social actors to a particular practice is not random, but can systematically exclude or include particular groups or categories of individuals. From a Disability Studies perspective, re-shaping practices is not just an academic exercise; it is done precisely in order to make those practices more accessible, and to literally 'recruit' a wider cross-section of disabled people as social actors. In particular, we are interested in the power imbalances in institutional practices such as assessments for disability support, which include professional and 'lay' users, and in ways of changing the institutional arrangements that dictate and structure how disabled people can take part in those practices.

\section{Methodology}

The central aim of our project [Name of Project] is to develop informed understanding of how disabling practices come about and are perpetuated, so that we can propose and actually make changes to those practices. This paper focuses on the identification of barriers facing disabled people, and the applicability of social practice theory to help understand how these barriers become naturalised and 'stuck', notwithstanding the existence of equality legislation. We also want to explore disabled people's own solutions, and understand better the conditions under which 'coproduction' can have an effect on practice.

Drawing on our findings, we will mention some of the problematic practices which are excluding different groups of disabled people, and we will show how we can start to account for these exclusions through the lens of social practice theories. Our insights into exclusionary practices and barriers are driven by the experiences of disabled people: we cannot know what is going wrong 
without involving and working with disabled people, and we are fortunate to have several disabled academics in the research team. Moreover, we are working specifically with [name of organisation] and with "co-production" groups, who enable us to include the views of disabled people throughout the project. In the spirit of debates about emancipatory and inclusive research (Barnes, C. 2004; Barton, 2005), we are aware that different forms of inclusion and active involvement will suit different groups (see Author et al., in press; Author 1, 2011). The central point for us is the contribution of disabled people's organisations, both within setting up the overall research agenda, but also by contributing their lived experience to our understanding of the exclusionary effect of social practices.

Each of the five empirical strands of research in our study explores different domains of life, and each involves different groups of disabled people. We aimed for variety here, both in sampling and methodology, since we wanted the empirical research to both stand in its own right, but also to serve as a canvas on which to explore the central ideas about social practice and change. In this paper, we draw on examples from just two of the five strands, which will be briefly described here.

The first strand [Name] has collected over 20 hours of video material of naturally occurring interactions which involve disabled people. Our aim here is to explore the fine detail of verbal and non-verbal interaction, as in Author (2011) and the ways in which it can exclude or facilitate the control and choices of disabled people. The material is diverse, and covers interactions at home between people with intellectual disability and their personal assistants, interactions during music making at school, between young disabled people and learning support assistants, and conversations that involve people with dementia largely filmed in group activities or day centres. We are engaging with two groups of disabled people, one a dementia research group, and the other a drama group of actors with intellectual disabilities. In both cases, they are reviewing video data from the project, and making suggestions based on their own experience of similar encounters, before remodelling those encounters to show how practices could be different.

The second strand, [Name] is taking a narrative inquiry approach (Trahar, 2013), with a research group formed of disabled students who are exploring their own and others' experiences of studying at university, and a disabled member of staff who is working with others to produce accounts from the staff point of view. Our goal here was to include a focus on social practices in which we ourselves are entailed, as academics at the university, and to avoid the danger of shaming groups of 'others' without acknowledging our own disabling practices. Like much of our project, there is an action approach here, with both staff and students tackling the inequities they find in the university, and recording the process of making those changes. 
Ethical issues across the various strands of this research relate to sensitivity of personal data from disabled people, the possibility of some individuals not being able to consent to the research, and of course the need for privacy and anonymity of data, particularly with regard to video data in which people may be recognisable. Each of the strands described here has been approved by different ethics committees, with '[Name]' approved by the national Social Care Research Ethics committee, and the second strand approved by the University Faculty committee; in accounts of the data in this paper, we have anonymized names and any personal details which could make individuals recognisable.

Drawing on the very varied data sets we have collected, we aim to suggest briefly how social practice theories can be used in different ways, to understand and to change the problems faced by disabled people.

\section{[Name of strand 1]}

People with intellectual disabilities, like others who are non-disabled, have individual goals and aspirations which are not extraordinary; in our video data, we see people going for a walk across a park, shopping in a supermarket, cooking their supper or managing their housework and their family. All of these activities could be considered as social practices; for instance, shopping is generally managed by constructing lists (either in one's head or on paper), ensuring you have enough money, going to a shop and choosing the items you need. In Shove et al.'s (2012) terms, it is made up of a material environment of shops and items to buy, along with the human competencies associated with shopping, and maybe the value of independently sourcing and paying for one's own needs. However, shopping as a social practice increasingly involves a multitude of ways that the activity could be enacted: 'shopping' could be done online, it could be paid for with a credit card or cash, some shops may be only accessible by car. Thus the interconnections between bundles of practices are immediately apparent in our everyday lives. The difference however for our participants with intellectual disabilities is that they often accomplish these social practices, and others, with the support of another person. An additional layer of interaction is going to be present; where a non-disabled person might pop into a supermarket and buy a pint of milk without saying a word, the practice for our participants often involves interaction with a professional - a personal assistant (PA) who accompanies them. It should of course be noted that this supported shopping scene only takes place because of the wider policy of personalisation which has allowed Paul to have access to funding for personal assistance. Our focus is on how the neoliberal goals of individual autonomy are then enacted in practice. 
In one video, we see a young man called 'Paul' who had two personal assistants with him when he went into the supermarket to buy a single donut, and was confronted with an aisle of bread and cakes, displayed on stacked shelves. On picking out a pack of four donuts, his PA commented that the shop only had packs of four, and reminded him that he only wanted one item to eat. After a few other false attempts, Paul's choice was directed towards the croissants, where he could buy just one to eat as a snack. In short, Paul's choices are re-shaped, in the interests of him choosing just a single item, and so he ends up buying something which was not his original choice. It should be pointed out here that in general Paul received excellent personalised support from his assistants, which gave him a chance to get out of his family home, and to enjoy many wider activities in the community.

The whole practice of 'choosing something from the supermarket' is constituted and comes into being through language as well as non-verbal actions such as taking the item from the shelf. We are analysing these extracts with the tools of Conversation Analysis (Sidnell and Stivers, 2012; Author 1, 2011) which enables us to consider the fine detail of how utterances are shaped by previous talk and how they shape subsequent interaction, the actions that talk accomplishes (e.g requests, offers, invitations, directives, etc.), and how these utterances are taken by each participant. Here is one very short part of the transcript:

Paul: $\quad$ ((Points to a 4 pack of donuts))

Paul: What about these?

Anne: $\quad$ They've only got four though

Robert: $\quad$ Ah well

Anne: $\quad$ And you only want one

Paul: $\quad$ (Can) only have one

Anne: What's the smallest amount they have

When Paul points to the donuts and says 'What about these?' he offers the PA a chance to express an opinion, to respond or to confirm his own choice. Thus it is not surprising that - Anne, the PA, takes up the next turn- as Paul's utterance had made a response conditionally relevant; it would have been quite rude not to respond. However, each time we have a turn at talk, we have freedom to use that 'slot' to do something slightly new, and Anne in fact says something that pulls against what Paul clearly wanted to hear, by saying 'They've only got four though'. Her turn problematizes Paul's choice by invoking quantity as the basis for not supporting/endorsing his proposed choice. 
This is further pursued in the following lines where Paul is given the reason for the non-acceptance of his choice ('and you only want one'), before initiating a new action of selecting an appropriately low numbered snack ('what's the lowest number they have').In some senses, the language used in any context both draws on the material context itself (in this case, a supermarket), but also constitutes and re-shapes the social practice within that context; in this case, shopping in a supermarket becomes something like "shopping wisely for a small or appropriate snack".

When discussing this extract with the co-production drama group, they disagreed amongst themselves on what was happening; some people strongly felt that Paul's right to choose was being overridden, while others felt that he needed to be advised by his PAs so that he did not choose four donuts, and eat them all at once. This raised a question about the practices of PAs in determining how Paul should follow his individual health care plan. Thus we started to explore how the social practice in the supermarket could be linked with other practices, such as dieting and personal health care.

Led by the views of the drama group, we could see how the layout of the supermarket, and the emphasis on cheap multi-packs, constrained what was possible for Paul to choose. Could we envisage a way in which our analysis might actually help to shift the social practice of shopping in a supermarket itself? Maybe a return to the 'shop of the past' where a shop assistant interacted and helped Paul to find what he wanted would have helped his choices. Perhaps that pack of donuts could even have been split! In musing on these possibilities, we came across an attempt by one UK supermarket to institute 'slow shopping' times on one day of the week, offering disabled or older people a chance to take their time and to have that personal customer service which perhaps Paul needed.

A social practice such as shopping can thus be shown to be performed via language and by interactions between individuals. We can capture these details in data via recordings of naturally occurring actions in everyday life; however, the way that practice is shaped in a broader sense is dependent on some much wider forces, including the provision of personal assistance via the social care system and the way supermarket shopping is organised, relating to economy of scale, access to global goods, and speed. Paul had to fit into a social practice that was 'normalised' on a population which did not include his particular needs.

\section{Misfitting, disability activism and social practices}

Garland-Thomson's 2011 notion of misfitting, which we mentioned in the context of disability theory, thus dovetails nicely with Shove et al.'s (2012) detailed analysis of elements of meanings, 
competences and technology which form particular social practices, helping us to see exactly how disabled people are excluded or how they 'misfit' (Garland-Thomson 2014) into existing social practices. In several parts of our study, moreover, disability activism is a key theme, as it is for Garland-Thomson, and we would contend that acts of resistance by disabled people themselves can often give us the best window to understand and re-configure a social practice. In our strand on [Name of Strand 2] a disabled student research group is actively promoting change in the university. One notable way of creating change was via a high-profile public event, the group used Forum Theatre, drawing on Boal's (1993) 'Theatre of the Oppressed' as a method to present some of the issues which they face in the University, inviting audience members to interact and suggest solutions.

When considering university education in general as a bundle of social practices, it must first be noted that universities are almost by definition 'exclusionary' spaces, where competition and individual merit are paramount. It is interesting that in recent decades in the UK, universities have expanded their remit, and deliberately made an attempt to embrace a wider section of the population, partly by simply expanding the number of places available overall. It was in that context which was open to reflection and change that our student group members were able to look, from the inside, at their own experience within a university.

One of the practices which they looked at was the identification and referral process to obtain disability support, which several of the group had experienced. The scene acted out in the Forum Theatre event involved firstly the personal tutor and student, with the latter concerned that they would not be able to complete an assessment, due to a chronic fatigue condition which has been progressing through the course of the year. Without asking the student to sit down, despite their acknowledged fatigue, the tutor refers them on to the Disability Support officer in the Faculty, whose office is in a different building. Again, material arrangements are key to understanding the 'misfit' of this particular social practice. The support officer was able to put adjustments in place for the assessment process, and so was helpful to the student; indeed, the personal competencies of the support officer were a key focus in the drama re-enactment. However, in order to obtain the right to these adjustments, there was a need for more form-filling and specifically for the student to be assessed by a qualified officer at Disability Services. Thus again a referral had to be made, time was wasted, and the student herself had to negotiate another encounter, within a building which she found increasingly difficult to access.

The social practices on display here could broadly be subsumed under the heading of 'referral for disability support', a practice that is tied uniquely to those social actors who identify as disabled. 
Several features of that practice stand out as important for Disability Studies. Firstly, a particular social practice can look and feel very different to one social actor, as compared with another. Being recruited to a social practice is not always a neutral affair, and the inequalities of access reflect the power imbalances between staff and students. The personal tutor and disability officers involved in this scenario may have felt they were carrying out the social practice in a way which was timely, student-centred and in line with the standardised procedure. In the re-enactment scenario, the personal tutor explained to the student what she needed to do, so that the assessment could be 'fair' both to her and to other students. From the student's point of view, however, there were elements of time, space and communication which she had to negotiate, creating distress and bodily discomfort. There are many social practices such as this one that we have examined in our project, where the shaping of the process lies in the hands of professionals, and the 'meaning' element of the practice becomes detrimental to the disabled person, who is made to feel that they are the problem. The disabled student in this case is in a considerably less powerful position than the professionals.

Nevertheless, the act of recounting and assembling this scenario, in order to re-enact it with members of the University staff and other visitors, was an act of considerable resistance. It enabled all participants to re-imagine the process of University support systems, indeed to question whether or not this particular social practice would have a place in a university where disabled students were truly 'included', and support systems unnecessary. Specifically, this and other similar scenarios of disabled students' experiences revealed the importance of values and language at the heart of social practices. Where a disabled student is seen as a 'problem' or a burden on the system, then their right to obtain education on an equal basis with others may be unwittingly undermined, via social practices which in this case entail physically travelling from one point on the campus to another, with the symbolic infrastructure of forms and paper evidence. In the university setting, we frequently hear the justification that practices need to be 'fair' for all students, so that one person is not unduly advantaged and allowed to succeed at the expense of others. In order to shift these practices, we need to do far more than simply tweak the material resources or slim down an unwieldy process of form filling. The value and rights of disabled people in a university have to be at the heart of change, with Shove's elements of 'meaning' absolutely central to the changes that are needed in order to create more inclusive educational settings.

\section{Conclusion}

What we hope to have touched on in this paper is the close union and common goals of disability theory and social practice theory. Both turn our attention from the deficits or skills of individuals, 
and indeed away from individual psychology, towards a consideration of how things get done, and how social practices are shaped. Both are concerned to unpack and trouble the assumptions in our everyday life that often get overlooked, and as we have shown, one of the ways in which we can do that is to pay attention to how things get talked about (Schatzki, 2017). Thus in the university setting, a common discourse on which practitioners draw is that of 'fairness', carrying with it the assumption that adjustments to support a disabled student may put them at an unfair advantage over others. In the supermarket, the discourse of 'choice' underpins what is happening, and is contained both within the material environment of the supermarket, but also in the talk that happens between personal assistant and shopper. That discourse of 'choice' as positive carries with it the assumption that the individual shopper can manage and indeed must conform to an acceptable choice of purchase. We would contend that these assumptions that are built into exclusionary practices are thus a key to unlock a clearer understanding of how they are shaped; discourses are the key to knowledge, orders which hold practices together and make meanings within them explicit (Schatzki, 2017).

As the examples and analysis in this paper show, there are also some limitations of social practice theories, when considered as vehicles for change; we would hope therefore that our insights in Disability Studies might contribute to Social Practice theory itself. For instance, Hui (2017) notes how variations within the way practices are enacted have 'meaningful boundaries' (p. 56), in that one can only push a particular practice so far, before it becomes something different. However, we would contend that much depends on who is permitted to determine those boundaries. The experiences and actions of disabled people show us how practices are routinely shaped around embedded and naturalised assumptions about who is a valid and valuable social actor. Being a student in a university for instance is premised on assumptions of individual achievement, and support structures are therefore 'add-on's, not to be mentioned or acknowledged, let alone celebrated.

We have also demonstrated in this paper how Social Practice theory helps Disability Studies to examine in more detail how practices are shaped, and indeed the data for this endeavour can consist of detailed recordings of naturally occurring interactions or alternatively can emerge from narratives or scenarios created from experience. We have also been interested to highlight the interconnections between different practices, and how that understanding might help us to lever changes. In our project, we wish to look beyond analysis towards the mechanisms of change, and specifically towards the goals of what is increasingly known as 'co-production' (Boyle et al. 2009). The rhetoric of co-production is of course easier to achieve than the reality (Scourfield 2015). 
However, the current authors are attempting to work closely with groups of different disabled people, in order to re-shape practices on their terms.

Turning again to Hui (2017), people are never defined just by one practice; instead, Hui shows how we all take part in multiple practices, and we may transfer 'skills or understandings that can be incorporated into a different practice' (p. 60). We would claim that this transfer is not a valueneutral act, but allows disabled people to bring their own ways of working, their specific insights and values, into practices as diverse as shopping and studying at a university. As Garland-Thomson (2014) points out, 'misfitting' can be considered not just a state, but an active becoming, a 'performance' carried out by the social actors whose bodies or minds are excluded by the way material objects and settings are constituted. As she points out, when we 'fit' into a prevailing social practice, it is unremarkable and can go unnoticed. Indeed, it could be argued that some of the disability-specific practices in universities and elsewhere are designed precisely to make disabled people invisible. However, 'when we experience misfitting, and recognize that disjuncture for its political potential, we expose the relational component and the fragility of fitting' (Garland-Thomson 2014, 597). Disabled people become visible, quite literally, as they unsettle and question the way things get done, and thus Disability Studies offers social practice theory a unique perspective on how the world could be.

\section{References}

Author 12011

Author 12017

Author 1 et al. in press.

Author 4 et al. 2016

Author 4 et al. 2017.

Abbott, D. (2013) “Nudge, nudge, wink, wink: love, sex and gay men with intellectual disabilities - a helping hand or a human right?" Journal of Intellectual Disability Research, 57 (II): 1079-87.

Alvesson, M. (2013) Understanding Organizational Culture, $2^{\text {nd }}$ ed. London: Sage.

Barnes, B. (2001) "Practice as collective action", pp 25-36 in The practice turn in contemporary theory, eds T Schatzki, K., C. Knorr and E. Von Savigny. New York: Routledge. 
Barnes, C. 2003 'What a Difference a Decade Makes: reflections on doing 'emancipatory' disability research', Disability \& Society, 18:1, 3-17.

Barton, L. 2005 'Emancipatory research and disabled people: some observations and questions'. Educational Review, 57 (3): 317-327.

Bhaskar, R. and Danermark, B. 2006. "Metatheory, Interdisciplinarity and Disability Research: A Critical Realist Perspective." Scandinavian Journal of Disability Research 8 (4): 278-297.

Boal, A. (1993) Theater of the Oppressed. New York: Theatre Communications Group.

Bott, S. 2016. "DRUK on tour: what people are saying at our events on UNCRPD." Accessed 19 December 2016. https://www.disabilityrightsuk.org/news/2016/october/what-people-are-sayingour-events-uncrpd.

Bourdieu, P. 1998. Practical Reason: on the Theory of Action. Translated by Cambridge: Polity Press. Boyle, D. and Harris, M. 2009. The Challenge of Co-production: how equal partnerships between professionals and the public are crucial to improving public services. London: National Endowment for Science, Technology and the Arts.

Care Quality Commission. 2014. The State of Health Care and Adult Social Care in England 2013/14. Presented to Parliament pursuant to section 83(4)(a) of Part 1 of the Health and Social Care Act 2008. https://www.gov.uk/government/publications

Crow, L. 1996. "Including all our lives: renewing the Social Model of Disability." Chapter 4 in Exploring the Divide, edited by Colin Barnes and Geof Mercer, 55-72. Leeds: The Disability Press.

Garland-Thomson, R. 2011. "Misfits: A Feminist Materialist Disability Concept." Hypatia 26 (3): 591609.

Garland-Thomson, R. 2014. "The Story of my Work: how I became disabled." Disability Studies Quarterly, 34 (2). doi:10.18061/dsq.v34i2.4254.

Giddens, A. 1988. "Goffman as a Systematic Social Theorist." Chapter 9 in Erving Goffman: Exploring the Interaction Order, edited by P. Drew and A. Wootton, 250-279. Cambridge: Polity Press.

Handy, C. (1993) Understanding Organizations, $4^{\text {th }}$ ed. London: Penguin.

Harwood, R. (2016) “Can international human rights law help restore access to justice for disabled workers?" Laws, 5 (17): 1-23. 
Housley, R. \& James-Smith, R. 2015. “Membership Categorisation and Methodological Reasoning in Research Team Interaction." Chapter 7, in Advances in Membership Categorisation Analysis, edited by R. Housley \& W. Fitzgerald, 151-73. London: Sage.

Holmes, J. (2006) “Workplace narratives, professional identity and relational practice", Chapter 6, pp 166-87, in Discourse and Identity, edited by A. De Fina, D. Schiffrin and M. Bamberg. Cambridge: Cambridge University Press.

Hui, A. (2017) "Variation and the intersection of practices", Chapter 4, pp 52-67 in The Nexus of Practices: connections, constellations, practitioners, edited by A. Hui, T. Schatzki and E. Shove. Oxford: Routledge.

Liebling, A. 2001. "Whose side are we on? Theory, practice and allegiances in prison research." British Journal of Criminology, 41: 472-484.

Lipsky, M. (1980) Street Level Bureaucracy: dilemmas of the individual in public services. New York: Russell Sage Foundation.

Moodley, J. \& Lauren Graham. 2015. The importance of intersectionality in disability and gender studies, Agenda, 29 (2): 24-33.

Oliver, M. 1990. The Politics of Disablement. Oxford: Butterworth-Heinemann

Oliver, M. 2013. "The social model of disability: thirty years on." Disability \& Society, 28 (7): 1024-26.

Reckwitz, A. 2002. "Toward a Theory of Social Practices: A Development in Culturalist Theorizing." European Journal of Social Theory 5 (2): 243-263.

Redley, M., Malna, E., Keeling, A and Pattni, P. (2012) “The voting rights of adults with intellectual disabilities: reflections on the arguments, and situation in Kenya and England and Wales", Journal of Intellectual Disability Research, 56 (II): 1026-35.

Riddell, S. and Watson, N. (2011) "Equality and Human Rights in Britain: Principles and Challenges", Social Policy \& Society, 10 (2): 193-203. 
Robillard, A. (1999) Meaning of a Disability: the lived experience of paralysis. Philadelphia: Temple Press.

Schatzki, T. 1996. Social Practices: A Wittgensteinian Approach to Human Activity and the Social. Cambridge: Cambridge University Press.

Schatzki, T. 2001. "Introduction: practice theory." in The Practice Turn in Contemporary Theory, edited by T. Schatzki, K. Cetina, and E. von Savigny, 1-14. London: Taylor \& Francis.

Schatzki, T. 2017. "Sayings, Texts and Discursive Formations", Chapter 9, pp 126-40 in The Nexus of Practices: connections, constellations, practitioners, edited by A. Hui, T. Schatzki and E. Shove.

Oxford: Routledge.

Shakespeare, T. (2006) Disability Rights and Wrongs. London: Routledge.

Scourfield, P. 2015. "Implementing Co-Production in Adult Social Care: An Example of MetaGovernance Failure?" Social Policy and Society, 14 (4): 541-554.

Shakespeare, T. 2006. Disability Rights and Wrongs. London: Routledge.

Shove, E. 2010. "Beyond the ABC: Climate Change Policy and Theories of Social Change." Environment \& Planning A 42 (6):1273-1285.

Shove, E. 2014. "Putting practice into policy: reconfiguring questions of consumption and climate change", Contemporary Social Science, 9 (4): 415-29.

Shove, E. and Pantzar, M. 2007. "Recruitment and reproduction: the careers and carriers of digital photography and floorball", Human Affairs, 17 (1): 154-67.

Shove, E., Pantzar, M. \& Watson, M. 2012. The Dynamics of Social Practice: everyday life and how it changes. London: Sage Publications.

Sidnell, J. and Stivers, T. 2012. The Handbook of Conversation Analysis. Wiley-Blackwell.

Thomas, C. 1999. Female Forms: Experiencing and understanding Disability. Buckingham: Open University Press.

Thomas, C. 2004. "How is disability understood? An examination of sociological approaches." Disability and Society, 19 (6): 569-583. 
Trahar, S. 2013. Preface in S.Trahar (ed.) Contextualising Narrative Inquiry: Developing Methodological Approaches for Local Contexts (ppx1-xx1)

United Nations. 2007. UN Convention on the Rights of Persons with Disabilities

http://www.un.org/disabilities/documents/convention/convoptprot-e.pdf

United Nations Committee on the Rights of Persons with Disabilities (2016) Inquiry concerning the

United Kingdom of Great Britain and Northern Ireland carried out by the Committee under article 6 of the Optional Protocol to the Convention. CRPD/C/15/R.2/Rev.1 [accessed

http://www.ohchr.org/EN/HRBodies/CRPD/Pages/InquiryProcedure.aspx]

Watson, N. 2003. "Daily Denials: the routinisation of oppression and resistance." Chapter 3 in Disability, Culture and Identity, edited by S. Riddell \& N. Watson, 34-52. London: Routledge. 